\title{
Clinical observation on the therapeutic effects of levamlodipine and amlodipine in mild and moderate hypertension.
}

\author{
Chang Hui, Ying-Qiang Guo, Zhi-Cai Yang, Xiao-Kang Ning, Li-Ming Yue* \\ Department of Cardiovascular Medicine, Affiliated Hospital of Shaanxi University of Chinese Medicine, Xianyang, PR \\ China
}

\begin{abstract}
Objective: This study aims to observe the clinical effects of levamlodipine and amlodipine in mild and moderate hypertension.

Methods: A total of 110 patients diagnosed with mild and moderate hypertension in our hospital from April 2015 to February 2017 were selected and randomly divided into control group and observation group by the odd-even method. The control group (55 cases) was treated with amlodipine in clinics, whereas the observation group (55 cases) was treated with levamlodipine. Finally, the evaluation results of blood pressure indexes, disease effect, treatment satisfaction, and blood index of the two groups were compared.

Results: The blood pressure indexes of the observation group significantly improved compared with that of the control group $(\mathrm{P}<\mathbf{0 . 0 5})$. The therapeutic effect of the observation group is $98.18 \%$, which is considerably higher than that of the control group $(\mathbf{7 6 . 3 6 \%})(\mathrm{P}<\mathbf{0 . 0 5})$. The treatment satisfaction of the observation group is $\mathbf{9 8 . 1 8 \%}$ while that of the control group is $72.73 \%(\mathrm{P}<0.05)$. The blood indexes of the observation group improved significantly compared with that of the control group $(\mathbf{P}<0.05)$.

Conclusions: Levamlodipine is superior to amlodipine in terms of the improvement of blood pressure indexes, disease effect, treatment satisfaction, and blood indexes in patients with mild and moderate hypertension. Thus, levamlodipine optimizes prognosis of patients with mild and moderate hypertension.
\end{abstract}

Keywords: Mild and moderate hypertension, Amlodipine, Levamlodipine, Clinical effect. Accepted on December 05, 2017

\section{Introduction}

Hypertension diseases are characteristic of remarkable high morbidity and difficult treatment [1]. Currently, drug therapy is widely applied to hypertension diseases, and several types of drugs that show significantly different clinical effects exist $[2,3]$. This study focuses on the comparison of amlodipine drugs and explores the clinical value of levamlodipine in mild and moderate hypertension [4]. Research results provide adequate assurances to increase prognosis of mild and moderate hypertension.

\section{Information and Methods}

\section{General information}

A total of 110 patients with mild and moderate hypertension in our hospital from April 2015 to February 2017 were selected and randomly divided into control group and observation group by the odd-even method. The control group (55 cases) included 42 males and 13 females with ages ranging 47-73 (56.13 \pm 1.19 ) in average. The observation group (55 cases) included 43 males and 12 females with ages ranging 49-79, (56.12 \pm 1.21$)$ in average. Two groups had no significant difference in gender and age $(\mathrm{P}<0.05)$.

\section{Selection and exclusion criteria}

Selection criteria: Relevant diagnosis criteria of hypertension meet mild and moderate conditions. All patients presented different degrees of dizziness, high blood pressure, and dim eyesight.

Exclusion criteria: Patients with serious organ function damages and drug allergy were excluded.

\section{Methods}

After hospitalization, the control group was treated with amlodipine while the observation group was treated with levamlodipine. Amlodipine was administered at $0.5 \mathrm{mg} / \mathrm{time}$ once every day. Levamlodipine was administered at $0.5 \mathrm{mg} /$ time once every day. 


\section{Evaluation standard}

Therapeutic effect controlled: Patients with mild and moderate hypertension get rid of series symptoms and blood pressure indexes were normal. Relieved: series symptoms and blood pressure indexes were all relieved. Ineffective: series symptoms remained and the disease was worsening.

Treatment satisfaction: Treatment satisfaction was invested by the self-made questionnaire. It has three levels: satisfying, acceptable, and unsatisfying.

Table 1. Comparison of the clinical evaluation results of blood pressure indexes between two groups $(\bar{x} \pm s, m m H g)$.

\begin{tabular}{|c|c|c|c|c|c|c|c|c|c|}
\hline \multirow[t]{2}{*}{ Groups } & \multirow[t]{2}{*}{$\mathbf{n}$} & \multicolumn{4}{|c|}{ Systolic pressure } & \multicolumn{4}{|c|}{ Diastolic pressure } \\
\hline & & Before & & After & & Before & & After & \\
\hline $\begin{array}{l}\text { Observation } \\
\text { group }\end{array}$ & 55 & $\begin{array}{l}153.03 \\
11.25\end{array}$ & \pm & $\begin{array}{l}127.51 \\
10.02\end{array}$ & \pm & $\begin{array}{l}89.15 \\
10.26\end{array}$ & \pm & $\begin{array}{l}70.02 \\
9.07\end{array}$ & \pm \\
\hline Control group & 55 & $\begin{array}{l}153.13 \\
11.16\end{array}$ & \pm & $\begin{array}{l}141.13 \\
10.17\end{array}$ & \pm & $\begin{array}{l}89.11 \\
10.20\end{array}$ & \pm & $\begin{array}{l}82.15 \\
8.26\end{array}$ & \pm \\
\hline $\mathrm{t}$ & & 0.0468 & & 7.0749 & & 0.0205 & & 7.3330 & \\
\hline$P$ & & $>0.05$ & & $<0.05$ & & $>0.05$ & & $<0.05$ & \\
\hline
\end{tabular}

\section{Statistical analysis}

Therapeutic outcomes of all patients with mild and moderate hypertension were analyzed by SPSS19.0. Enumeration data (e.g. therapeutic effect) of the two groups were expressed in $\%$ and examined by $\chi^{2}$-test. Measurement data (e.g. blood pressure indexes) were expressed by $\pm \mathrm{s}$ and examined by $\mathrm{t}$ test. $\quad \mathrm{P}<0.05$ indicates statistically significant difference between two groups.

\section{Results}

\section{Blood pressure indexes}

The blood pressure indexes of the observation group significantly improved compared with the control group $(\mathrm{P}<0.05)$ (Table 1).

\section{Therapeutic effect}

The therapeutic effect of the observation group was $98.18 \%$, which was considerably higher than that of the control group $(76.36 \%)(\mathrm{P}<0.05)$ (Table 2$)$.

\section{Treatment satisfaction}

The treatment satisfaction of the control group was $72.73 \%$ and that of the observation group was $98.18 \%$ showing significant difference $(\mathrm{P}<0.05)$ (Table 3$)$.

\section{Blood indexes}

The blood indexes of the observation group improved significantly compared with that of the control group $(\mathrm{P}<0.05)$ (Table 4).

Table 2. Comparison of the therapeutic effects between two groups (cases).

\begin{tabular}{lccccc}
\hline Groups & $\mathbf{n}$ & Controlled & Relieved & Ineffective & Total efficiency (\%) \\
\hline Observation group & 55 & 45 & 9 & 1 & 98.18 \\
\hline Control group & 55 & 32 & 10 & 13 & 76.36 \\
\hline$X^{2}$ & & & & 11.7857 \\
\hline$P$ & & & $<0.05$ &
\end{tabular}

Table 3. Comparison of the treatment satisfaction values between the two groups (cases).

\begin{tabular}{llllll}
\hline Groups & $\mathbf{n}$ & Satisfying & Acceptable & Unsatisfying & Total satisfaction (\%) \\
\hline Observation group & 55 & 41 & 13 & 1 & 98.18 \\
\hline Control group & 55 & 25 & 15 & 15 & 72.73 \\
\hline$X^{2}$ & & & & 14.3351 \\
\hline$P$ & & & $<05$ \\
\hline
\end{tabular}

Table 4. Comparison of the blood indexes between the two groups $(\bar{x} \pm s)$.

\begin{tabular}{llllll}
\hline Groups & Time & $\mathbf{n}$ & $\mathbf{K}+(\mathbf{m m o l} / \mathbf{L})$ & Hemoglobin $(\mathbf{g} / \mathbf{L})$ & $\mathbf{R B C}\left(\times \mathbf{1 0} \mathbf{1 2}^{12} \mathbf{L}\right)$ \\
\hline Observation & Before & 55 & $4.60 \pm 0.45$ & $141.12 \pm 11.22$ & $4.25 \pm 0.50$ \\
\cline { 2 - 5 } & After & 55 & $4.45 \pm 0.16$ & $153.11 \pm 12.25$ & $5.02 \pm 0.55$ \\
\hline
\end{tabular}




\begin{tabular}{|c|c|c|c|c|c|}
\hline $\mathrm{t}$ & & & 2.3292 & 5.3528 & 7.6825 \\
\hline$P$ & & & $<0.05$ & $<0.05$ & $<0.05$ \\
\hline \multirow[t]{2}{*}{ Control } & Before & 55 & $4.59 \pm 0.40$ & $141.52 \pm 11.20$ & $4.52 \pm 0.51$ \\
\hline & After & 55 & $4.39 \pm 0.17$ & $153.92 \pm 13.45$ & $5.07 \pm 0.53$ \\
\hline $\mathrm{t}$ & & & 3.4126 & 5.2541 & 5.5455 \\
\hline $\mathrm{P}$ & & & $<0.05$ & $<0.05$ & $<0.05$ \\
\hline
\end{tabular}

\section{Discussions}

As a clinical chronic disease, hypertension disease has high probability to cause cardiovascular and cerebrovascular diseases, thereby greatly threatening the safety of patients [5]. According to analysis, many causes of hypertension exist, mainly including dietary structure, genetic factors, and psychological stresses. Antihypertensive drugs are needed in clinical treatment. However, different drugs contribute different clinical effects because of the different mechanisms of action [6]. Therefore, ensuring safety and reasonability of antihypertensive drugs is highly significant.

Amlodipine is frequently used as a kind of antagonist and can achieve outstanding antihypertensive efficiency. Based on the analysis of the mechanism of action, amlodipine mainly expands the arteries and blood capillaries to reduce blood pressure [7]. In addition, it can dramatically reduce myocardial oxygen consumption of patients. However, no definite effect has been achieved in view of the series effect of blood pressure indexes. Under this circumstance, levamlodipine is widely used to treat hypertension diseases [8,9]. As a new antagonist, it can directly act on cells of patients and interdict a series of modular conversions. It can effectively reduce total calcium loss and adopt selective control to the blood vessels of patients. Moreover, it has persistent utility and significant effect without causing damage to the organs of patients [10]. No adverse drug reaction has been detected.

In this study, the blood pressure indexes of the observation group significantly improved compared with that of the control group $(\mathrm{P}<0.05)$. The therapeutic effect of the observation group is $98.18 \%$, which is considerably higher than that of the control group $(76.36 \%) \quad(\mathrm{P}<0.05)$. The observation group reports $98.18 \%$ treatment satisfaction compared with $72.73 \%$ of the control group $(\mathrm{P}<0.05)$. The blood indexes of the observation group improved significantly compared with that of the control group $(\mathrm{P}<0.05)$. These results prove the high clinical effect of levamlodipine to hypertension.

Studies of therapies to hypertension demonstrated that associate supporting therapy has significant values to the rehabilitation of patients. Specifically, (1) it ensures reasonable diet of patients and restricts daily intake of energies. It effectively reduces intakes of corn and sugar. To prevent growth of blood fat indexes, the total intake of fats is strictly limited, thereby greatly reducing cholesterol level, which can prevent stroke and thrombus of patients. (2) Patients are asked to do relevant exercises. Appropriate exercise type is determined according to disease types, thus facilitating blood circulation, strengthening muscle performance, and improving gastrointestinal motility. (3) Patients give up smoking and alcohol drinking and maintain a pleasant mood. Listening to music and broadcasting is suggested to relieve mood, which can stabilize the blood pressure levels of patients.

\section{Conclusion}

In a word, levamlodipine is superior to amlodipine with respect to the improvement of blood pressure indexes, disease effect, treatment satisfaction, and blood indexes in patients with mild and moderate hypertension. Levamlodipine also shows high therapeutic effect to hypertension.

\section{References}

1. Rayner B, Ramesar R. The importance of G proteincoupled receptor kinase 4 (GRK4) in pathogenesis of salt sensitivity, salt sensitive hypertension and response to antihypertensive treatment. Int $\mathrm{J}$ Mol Sci 2015; 16: 5741-5749.

2. Kjeldsen SE, Aksnes TA, Ruilope LM. Clinical implications of the 2013 ESH/ESC hypertension guidelines: targets, choice of therapy, and blood pressure monitoring. Drugs R D 2014; 14: 31-43.

3. Aydemir Ö. Determination of the two most discriminative directions of the cursor movement imagery tasks. Biomed Res 2016; 27: S16-S21.

4. Yu Q, Yin G, Zhang P, Song Z, Chen Y, Zhang D, Hu W. Distinct associations between hypertension and obstructive sleep apnea in male and female patients. PLoS One 2014; 9: e113076.

5. Arain MI, Ghoto MA, Dayo A. Evaluation of awareness regarding hypertension and their therapy among hypertensive patients at hospital of Hyderabad, Pakistan. Lat Am J Pharm 2017; 36: 1942-1946.

6. Qi Y, Zhang X. Determination of enantiomeric impurity of levamlodipine besylate bulk drug by capillary electrophoresis using carboxymethyl- $\beta$-cyclodextrin. Cell Biochem Biophys 2014; 70: 1633-1637.

7. Sheejakumari V, Gomathi S. Brain tumor detection from MRI images using histon based segmentation and modified neural network. Biomed Res 2016; 27: S1-S9.

8. Hromadnikova I, Kotlabova K, Ivankova K, Vedmetskaya Y, Krofta L. Profiling of cardiovascular and cerebrovascular disease associated microRNA expression 
in umbilical cord blood in gestational hypertension, preeclampsia and fetal growth restriction. Int $\mathrm{J}$ Cardiol 2017; 249: 402-409.

9. Trauthman SC, Piovezan AP, Becker IRT, Martins LP, Galato D. Pharmacotherapy for hypertension and diabetes in a national health care system in Brazil: Emphasis on patient access to prescription medications. Lat Am J Pharm 2014; 33: 492-498.

10. Wu W, Jiang S, Zhao Q, Zhang K, Wei X, Zhou T, Liu D, Zhou H, Zeng Q, Cheng L, Miao X, Lu Q. Environmental exposure to metals and the risk of hypertension: A cross-sectional study in China. Environ Pollut 2017; 233: 670-678.

\section{*Correspondence to}

Li-Ming Yue

Department of Cardiovascular Medicine

Affiliated Hospital of Shaanxi University of Chinese Medicine PR China 